\title{
Editorial
}

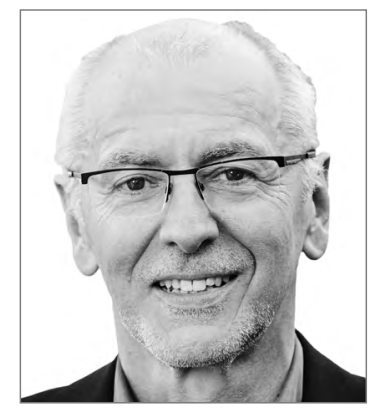

\section{ARMIN GRUNWALD}

Institut für Technikfolgenabschätzung und Systemanalyse (ITAS), Karlsruher Institut für Technologie (KIT) (armin.grunwald@kit.edu)

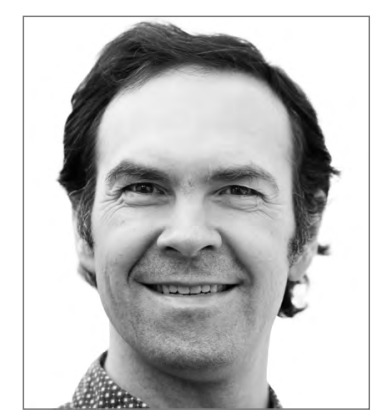

ULRICH UFER

Institut für Technikfolgenabschätzung und Systemanalyse (ITAS), Karlsruher Institut für Technologie (KIT)

(ulrich.ufer@kit.edu)

This is an article distributed under the terms of the Creative Commons Attribution License CCBY 4.0 (https://creativecommons.org/ licenses/by/4.0/)

http://dx.doi.org/10.14512/tatup.29.1.3 ie Covid-19-Pandemie fordert weltweit viele tausend Tote, bringt Gesundheitssysteme an ihre Grenzen, reduziert das öffentliche Leben drastisch und dominiert die Medien. Auch Universitäten und Forschungseinrichtungen arbeiten unter großen Einschränkungen.

Unter den Bedingungen von Unsicherheit und steigenden Infektionszahlen heute, am 18. März, die aktuelle Situation aus Perspektive der Technikfolgenabschätzung (TA) zu kommentieren, ist an sich ein unsicheres Unterfangen. Angesichts der Beschleunigung der Ereignisse könnte am Drucktermin vieles schon überholt sein, vielleicht stellen die ,gegenwärtigen Zukünfte‘ nur Momentaufnahmen dar.

Drei Beobachtungen der letzten Wochen möchten wir hier nennen, die über die eher trivialen, wenn auch real hoch relevanten, Dinge hinausgehen, z. B. dass mehr Vorsorge in der Verfügbarkeit von Mundschutzmasken angesagt sein muss.

Erstens: Das Coronavirus zeigt deutlich, wie die Fragilität moderner globaler Gesellschaften weitgehend von der Annahme verdrängt wurde, alles würde schon immer weiter so funktionieren. Obwohl die ,Komprimierung von Zeit und Raum“ seit Jahrzehnten den globalisierten Personen- und Warenverkehr charakterisiert, hatten dennoch auch viele Expertinnen und Experten noch vor wenigen Wochen nicht erkannt, dass ein Virus aus einer bisher weitgehend unbekannten chinesischen Provinz unser Leben auf den Kopf stellen könnte. Entsprechend wurde das Vorsorgeprinzip lange außer Acht gelassen, zu lange. Sich in Sicherheit wähnen, ist kein guter Ratgeber.

Zweitens: Ein Grundanliegen der TA ist es, auf signifikante systemische Risiken bei gleichzeitig als gering wahrgenommener individueller Gefährdung hinzuweisen, z. B. beim Thema Nachhaltigkeit. Aktuelle Einschränkungen individueller Freiheiten zur Entlastung des Gesundheitssystems zeigen die gesellschaftliche und politische Relevanz dieser Zusammenhänge überdeutlich.

Drittens: Ein Loblied auf die Digitalisierung! Interaktive digitale Formate für Information und Besprechungen mit schnellem Datenaustausch sind gegenwärtig essenziell. Aber wie steril, teils ineffektiv und irgendwie humorlos sind die digitalen Ersatzformate im ausschließlichen Gebrauch, wie reduziert ihre Erfahrungswelt, z. B. bei digitalen Gottesdiensten oder Familienfeiern. Ein Loblied auf die analoge Welt!

Für die TA, aber auch darüber hinaus, heißt dies: das Vorsorgeprinzip ernst zu nehmen und zu begreifen, dass Digitalisierung die analoge Welt bereichert, diese aber nicht ersetzen kann.

Armin Grunwald und Ulrich Ufer 